\title{
THE FORMATION OF INTERMEDIATE AND DEEP EARTHQUAKE ZONE IN RELATION TO THE GEOLOGIC DEVELOPMENT OF EAST ASIA SINCE MESOZOIC
}

\author{
Yasumoto Suzuki, Kisaburo Kodama, and Takashi Mitsunashi \\ Geological Survey of Japan, Tokyo, Japan \\ (Received July 18, 1978; Revised August 22, 1978)
}

\begin{abstract}
The intermediate and deep earthquake zone comes into existence under the condition that the continental side upheaves and the oceanic side subsides, judging from the geologic development of East Asia including the Japanese Islands since the Mesozoic age.

The authors try an experiment by F.E.M. to examine the internal condition accompanied by the vertical movement in the deeper part of the earth and explain the geologic development of East Asia including the Japanese Islands and the earthquake zone.
\end{abstract}

\section{Introduction}

It has often been pointed out that the geologic development of East Asia was intimately related to that of the Japanese Islands (MinAto et al., 1965). The intermediate and deep earthquake zone runs parallel to the island arcs and dips away from the trench toward the Asiatic continent. The tectonic and igneous activities of East Asia including the Japanese Islands since the Mesozoic took place parallel to the zone. These phenomena suggest that the geologic development of East Asia should be explained in relation to the intermediate and deep earthquake zone.

In this paper the authors propose a model to explain the formation of intermediate and deep earthquake zone in relation to the geologic development of East Asia since the Mesozoic age. They tried an experiment to explain the internal condition accompanied by vertical movement situated at deep place in the lower mantle beneath the region.

\section{Geodynamic Process}

The paleogeography during the Late Paleozoic period showed that marine geosynclinal environment prevailed on China and its adjacent areas, including the Japanese Islands (Minato et al., 1965). Then the sea regressed from East Asia toward east and south, and inland basins filled with thick nonmarine clastic sediments deposited there during the Mesozoic period. On the other hand, marine geosynclinal condition existed successively along the outer zone of the Japanese and Rhyukyu Islands. The transitional zone between them was in shallow marine, brackish and fresh water environments.

These movements were accompanied by intense volcanism of andesites, dacites and rhyolites, and intrusion of granitic rocks in the area from the inner zone of the island arcs to the East Asiatic continental region. The geosynclinal region along the outer zone of the island arcs were intruded by basalts and serpentinites. 
Similar tectonic and igneous activities were repeated at the those areas throughout the Paleogene age.

In the middle of the Tertiary, intense faulting, which was accompanied by andesitic, dacitic and rhyolitic volcanisms occurred along the island arcs, and then geosynclinal subsidence took place. In the continental region, Neogene and Quaternary basins were formed and filled with nonmarine clastic sediments. Alkali olivine basalts intruded and flowed out on the area from the inner zone of the island arcs to the continental region.

In the Quaternary age, the island arcs began to uplift into mountain ranges and volcanic zones appeared there.

Sedimentary basins which have been formed in the continental region of East Asia since the Mesozoic age are characterized by very large and gentle undulated structures which are steeply inclined and often cut by thrust faults along their margins. On the other hand the island arcs region is marked by steep folds and thrust faults.

As is well known, the intermediate and deep earthquake zones run parallel to the island arcs and dip away from trenches toward the continent. The Mesozoic and Cenozoic crustal movements and igneous activities take place parallel to the earthquake zones, and their width reaches more than $2,000 \mathrm{~km}$ (Fig. 1).

These facts show that the earthquake zones have come into existence under the con-

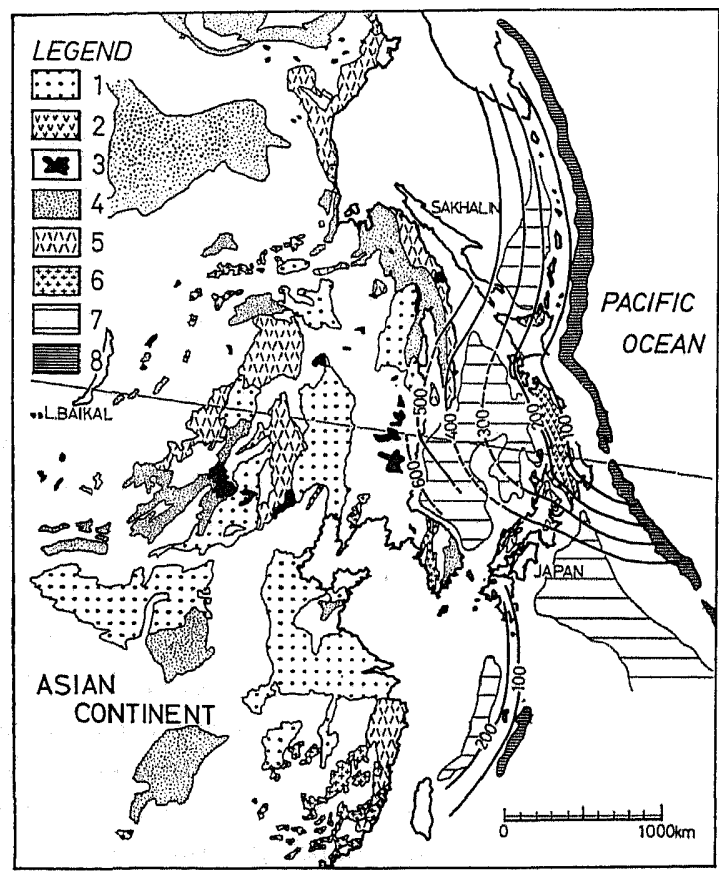

Fig. 1. The outline of geology of East Asia and the isobath lines of the intermediate and deep earthquake zone. 1, Tertiary and Quaternary basins; 2, Tertiary volcanics; 3, Tertiary and Quaternary alkali olivine basalts; 4, Mesozoic basins; 5 , Mesozoic and Paleogene volcanics; 6, Mesozoic and Paleogene granites; 7, Marginal sea; 8, Trench. 


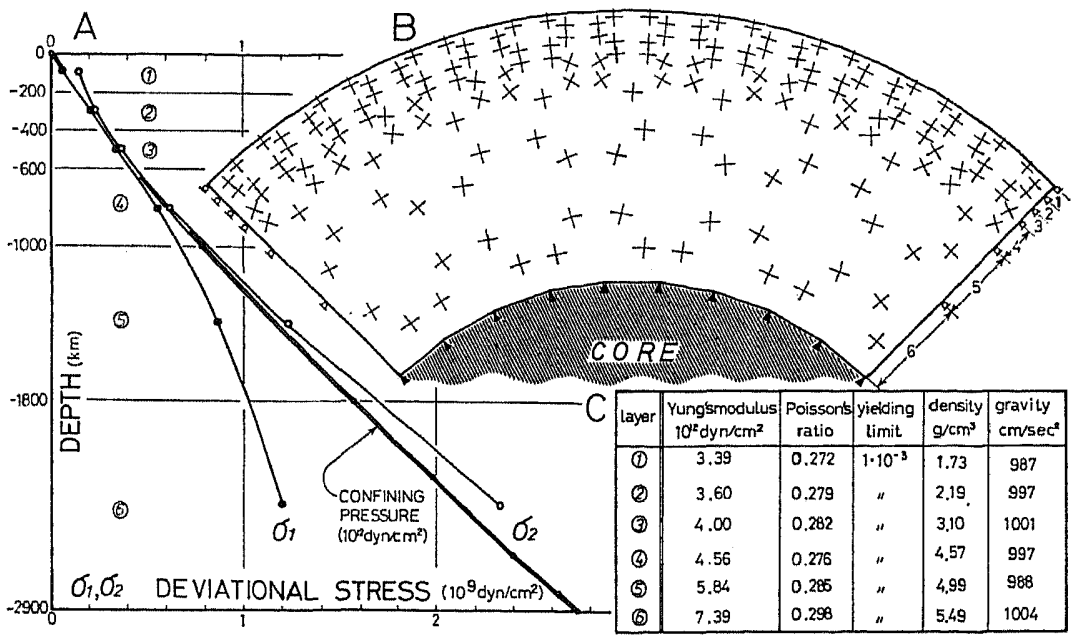

Fig. 2. The initial stress state under the gravity field. A, principal stress value; $\mathrm{B}$, orientations of principal stress; C, physical parameters for layered earth, calculated after BULLEN (1965).

dition of uplift of the continent and subsidence of the ocean. The authors think that its great width is resulted from very deep process in the earth, so they tried to study the internal condition due to uplift and subsidence on the surface of the earth's core.

\section{Tectonic Model}

According to the geodynamic process mentioned above, the authors modelled crust and mantle by means of two-dimensional plane-strain finite element approximation. The model is perpendicular to the marginal tectonic zone of the Asiatic continent, and a quardrant of the earth with a depth of 2,900 km (Fig. 2).

The crust and mantle are divided into six layers, each of which is assumed to behave as perfect plastic material after a slight elastic deformation. Elastic parameters and yielding limits are given in the table of Fig. 2 after BuLLEN (1965).

Non-tectonic initial stresses are obtained when all elements are deformed toward the earth's center by their own weight where displacements at the points on the core's surface are restricted to zero. The directions of maximum compressive stress are horizontal in the shallow part, but vertical in the deeper part of the mantle (Fig. 2). Though the magnitude of deviatric stress is far less than that of confining pressure, it has important effect upon the applied tectonic stress distributions.

Various kind of vertical deformation are applied on the surface of the core according to the geodynamic process mentioned in the previous section.

\section{Numerical Results}

Figure 3 shows the deformation of the earth's surface when the surface of the core is displaced up to $\pm 8 \mathrm{~km}$ in vertical direction. Vertical displacement on the earth's surface reach $\pm 6 \mathrm{~km}$ and a wide flexural zone is formed in the mantle. It is noticeable that such 


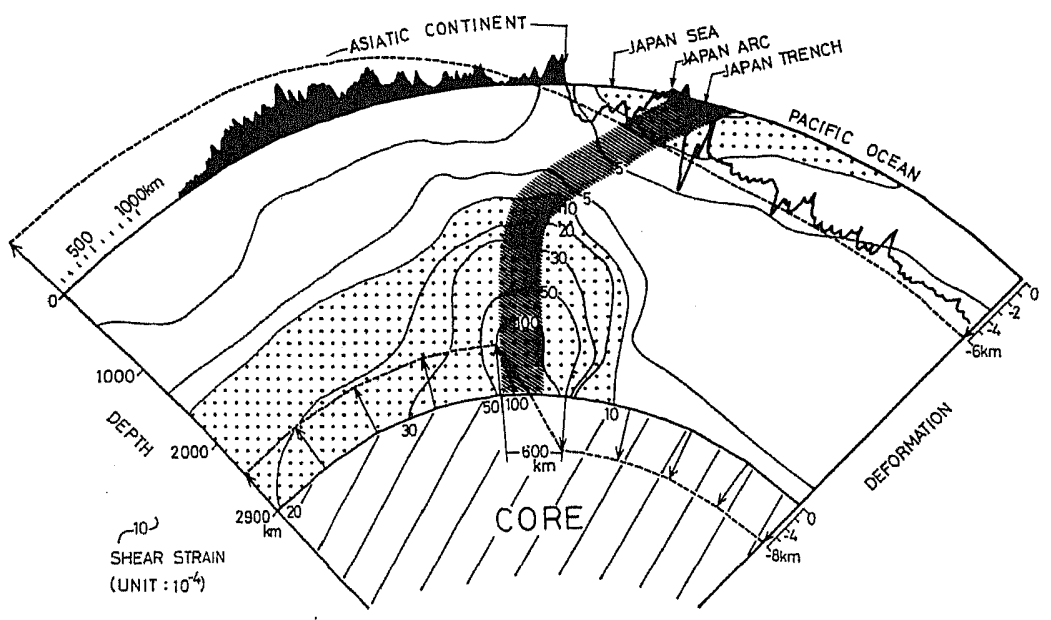

Fig. 3. Deformation and strain distributions.

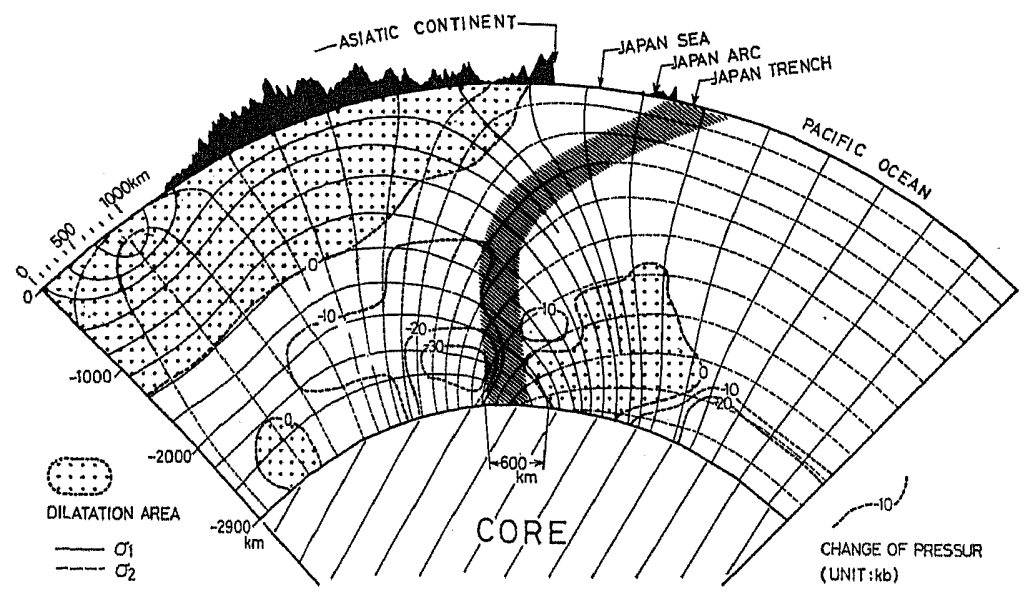

Fig. 4. Principal stress trajectories. Contour lines show the change of mean stress.

a slight displacement on the surface of core gives rise to considerable deformations in the mantle and on the earth's surface.

The distribution of shear strain is also shown in the figure. One of two maxima of shear strain occurs on the step of deformation of the core and the other around the upward concave hinge of the earth's surface, so a continuous shear concentrated zone is defined by connecting the greatest parts of shear strain at each depth (shaded zone in Fig. 3) as pointed out already in the previous paper (Kodama and Suzukr, 1977). This zone is nearly vertical in the lower mantle but gently inclined in the shallow part less than $1,000 \mathrm{~km}$ in depth. It might correspond to the intermediate and deep earthquake zone.

Three principal stresses are compressive, though the horizontal stresses are reduced near the surface of the uplifted region. Figure 4 shows that the maximum compressive 
stresses are horizontal in the subsided region, vertical in the uplifted region, and inclined in the transitional region between them. The maximum compressive stress runs obliquely to the shear zone near the earth's surface, while they are inclined and parallel to the shear zone in the lower part more than $400 \mathrm{~km}$ deep. These stress distributions are compared with those deduced from $\mathrm{P}$-wave radiation pattern under the Japanese Islands and their neighbours (ICHIKAWA, 1971).

The change of confining pressure is also shown in Fig. 4. It shows that the progress of vertical deformation is accompanied by the formation of dilatational area under the uplifted region, and increase of confining pressure under the subsiding region. When the surface of the core is uplifted $+8 \mathrm{~km}$, dilatational area reaches $1,500 \mathrm{~km}$ in depth and pressure decrease amounts to 5 kbar near the convex hinge of the earth's surface.

\section{Discussions and Conclusions}

As stated above, the strain and stress distribution in the uplifted region are in a striking contrast to those in the subsided area. The uplifted region is characterized by horizontal extension and release of confining pressure. These conditions might result in the formation of large graben and horst structures and intensive volcanic activities near the earth's surface. They are just the geologic phenomena in the marginal region of the Asiatic continent since the Mesozoic age. On the contrary, stable tectonics may be attributed to the increase of confining pressure throughout the subsided region as in the Pacific Ocean.

The topography of the transitional zone, which consists of marginal seas and island arcs, is too complicated to be compared with the corresponding part gently deformed on the model. It may be due to some shallower tectonic conditions caused by the deep process. Figure 5 shows a model in which the boundary displacements are applied at depth of $1,000 \mathrm{~km}$ and the width of flexural step is narrowed. Such flexural step may be expected within the shear concentrated zone in the former model at the advanced stage of core's deformation. It might be the case of local deformation such as the island arcs including the marginal sea.

KAULA (1969) showed a map of the earth's gravity anomalies based on a combination of satellite data and terrestrial gravimetry. He examined the relation between tectonic classification and main feature of the earth's gravity and pointed out that dominant gravity positive are markedly asssociated with recent geologic activity, especially in the trench and island arcs. Kaula considered that these global scale gravity variations were

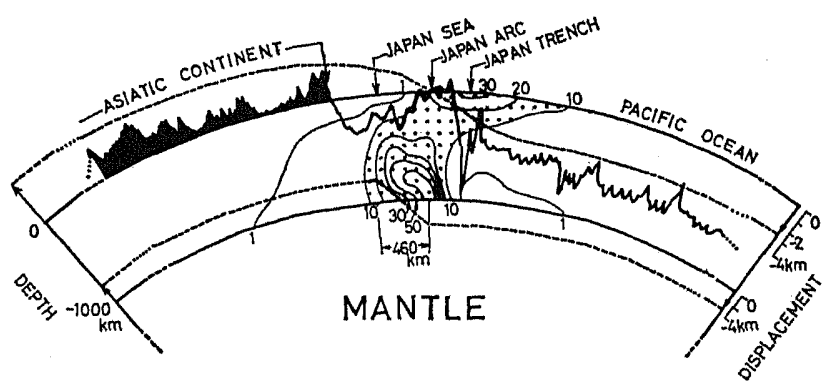

Fig. 5. A modified model to explain the formation of island arcs and marginal sea. 
used by upper mantle density variations which may be due to thermal expansion and intraction, or some lateral transfer of mantle material.

It is noticeable that mild but substantial positive anomalies distribute along the Circum acific orogenic belt and gravity deficiency appeares in the north west or north east Pacific cean in the Kaula's map (Fig. I of KAULA, 1969). These worldwide gravity anomalies ay be supposed to be caused by the tectonic deformations in the deep part of the lower antle during long geologic period as the present model.

According to the model, the intermediate and deep earthquake zone correspond to potential zone where shear strain is the highest at each depth and many fractures are :pected to occur. Nagumo (1972) discussed the high- $Q$, high-V properties of the deep ismic zone (UTSU, 1971) and explained them by the saturation of the pore/crack space $>\mathrm{H}_{2} \mathrm{O}$ and/or magma. The presence of these conditions may be explained reasonablly 7 the present model.

In this paper the authors propose a model in which the formation of intermediate Id deep seismic zone and geodynamic process near the earth's surface are explained by nple vertical movement in the deep beneath the lower mantle. It is hoped that this mewhat tentative model will assist in more analytic interpretations of the tectonics of cpanese Islands and adjacent areas.

This paper lacks in the discussion of the cause of deformation of core-mantle boundary. sme convective current or thermal expansion in the outer core may be supposed to result such boundary deformation, but precise discussions will be done when the relation stween the deep tectonic process and surface geology or extent and magnitude of deep fformations are examined more distinctly for the future.

The authors express their sincere thanks to Prof. Yukinori Fujita, Niigata University and Prof. Shozaburo tgumo, the Earthquake Research Institute, University of Tokyo for offering many valuable suggestions. ley extend their thanks to Mrs. Kazunori Kobayashi and Masahiko Tsuboi for numerous calculating works.

\section{REFERENCES}

LLEN, K.E., An Introduction to the Theory of Seismology, 3rd ed., 381 pp., Cambridge University Press, London, 1965.

HIKAWA, M., Reanalyses of mechanism of earthquakes which occurred in and near Japan, and statistical studies on the nodal plane solutions obtained 1926-1968, Geophys. Mag., 35, 207-274, 1971.

IULA, W.M., A tectonic classification of the main features of the earth's gravitational field, J. Geophys. Res., 74, 4807-4826, 1969.

JDAMA, K. and Y. SuzUKr, Formation of the deep earthquake zone due to mantle diaprism, Bull. Geol. Surv. Jpn., 28, 795-810, 1977.

inato, M., M. Gorat, and M. Hunafashi (eds.), The Geologic Development of Japanese Islands, 442 pp., Tsukiji-Shokan, Tokyo, 1965.

เGUMO, S., An interpretation of high- $Q$, high- $V$ of deep seismic surface, in Izu-Peninsula, edited by $M$. Hoshino and H. Aoki, pp. 305-310, Tokai University Press, Tokyo, 1972.

ssu, T., Some characteristics of earthquake occurrence and anomalous structure of the upper mantle in Japan, in Island Arcs and the Marginal Sea, edited by S. Asano and G.B. Udintsev, pp. 201-214, Tokai University Press, Tokyo, 1971. 